\title{
Olfactory Epithelium Grafts in the Cerebral Cortex: An Immunohistochemical Analysis
}

\section{Citation}

Holbrook, Eric H., Laurence J. DiNardo, and Richard M. Costanzo. 2001. “Olfactory Epithelium Grafts in the Cerebral Cortex: An Immunohistochemical Analysis." The Laryngoscope 111 (11) (November): 1964-1969. doi:10.1097/00005537-200111000-00018.

\section{Published Version}

doi:10.1097/00005537-200111000-00018

\section{Permanent link}

http://nrs.harvard.edu/urn-3:HUL.InstRepos:32697815

\section{Terms of Use}

This article was downloaded from Harvard University's DASH repository, and is made available under the terms and conditions applicable to Other Posted Material, as set forth at http:// nrs.harvard.edu/urn-3:HUL.InstRepos:dash.current.terms-of-use\#LAA

\section{Share Your Story}

The Harvard community has made this article openly available.

Please share how this access benefits you. Submit a story.

Accessibility 


\title{
Olfactory Epithelium Grafts in the Cerebral Cortex: An Immunohistochemical Analysis
}

\author{
Eric H. Holbrook, MD, Laurence J. DiNardo, MD, and Richard M. Costanzo, PhD \\ From the Departments of Otolaryngology-Head and Neck Surgery (E.H.H., L.J.D.) and Physiology \\ (R.M.C.), Virginia Commonwealth University, Medical College of Virginia Campus, Richmond, \\ Virginia, U.S.A
}

\begin{abstract}
Objective-To develop an alternative model for studying the regenerative capacity of olfactory neurons.

Study Design-An immunohistochemical analysis of mouse olfactory epithelium transplanted to the cerebral cortex.

Methods-Strips of olfactory epithelium removed from donor mice at postnatal day 5 to day 20 were inserted into the parietal cortex of adult mice. Recipient animals were allowed to survive for 25 to 120 days and then perfused with $4 \%$ paraformaldehyde 1 hour after bromodeoxyuridine injection. The brains were processed, and frozen sections were obtained. Sections through transplant tissue were analyzed using immunohistochemistry and compared with normal olfactory epithelium.

Results-Graft survival approached $85 \%$ with mature olfactory neurons detected in $35 \%$ of the transplants stained for olfactory marker protein. Transplant epithelium resembled normal olfactory epithelium containing mature olfactory neurons and axon bundles.
\end{abstract}

Conclusions-Studies of olfactory neuron regeneration have been limited by the inability to produce cultures with long-term viability. Olfactory epithelial grafts to the cerebral cortex provide an alternative approach to the study of olfactory neuron regeneration.

\section{Keywords}

Olfactory; immunohistochemistry; transplants; regeneration; epithelium

\section{INTRODUCTION}

It has been estimated that roughly two million Americans suffer from loss, decrease, or distortion of the sense of smell or taste, or both. ${ }^{1}$ The loss of olfaction can be debilitating. Anosmic individuals are unable to detect smoke, gas leaks, spoiled foods, or noxious chemicals, with possible disastrous outcomes. The psychological loss of pleasant olfactory experiences alone can cause depression, ${ }^{2}$ and the inability to detect one's own body odor or proper amount of perfumes or colognes can have a dramatic effect on social relations. Individuals in certain occupations, such as food preparers and perfumers, depend on their ability to smell. ${ }^{2}$

(C) 2001 The American Laryngological, Rhinological and Otological Society, Inc.

Send Correspondence to Richard M. Costanzo, PhD, Department of Physiology, School of Medicine, Virginia Commonwealth University, Richmond, VA 23298-0551, U.S.A. rcostanz@ hsc.vcu.edu.

Presented at the 104th Annual Meeting of the American Laryngological, Rhinological and Otological Society, Inc., Palm Desert,

California, May 15, 2001. 
The sense of smell relies on receptor neurons in the olfactory epithelium that establish direct synaptic connections with cells in the brain. The olfactory epithelium has the unique ability to replace these neurons throughout the life of an organism. ${ }^{3}$ In fact, the stem cells of this epithelium have the ability to replace the entire cellular constituent of the epithelium including supporting cells and olfactory receptor neurons. ${ }^{4,5}$ This pluripotent nature of the basal cells makes the olfactory epithelium a unique model for studying neuronal regeneration, as well as for studying chemosensory disease.

To closely study the regenerative capacity of this epithelium, multiple attempts to transplant or culture these cells have been tried with variable success. Epithelial transplants to the anterior chamber of the eye $e^{6,7}$ and surface of the brain ${ }^{8}$ have demonstrated the successful growth of olfactory neuroepithelium. Cell suspensions have shown some capacity for survival when injected in the brain, ${ }^{9}$ and suspensions of olfactory basal cells infused into the nasal cavity after chemical lesion have been shown to retain regenerative capacity. ${ }^{4}$ Cell cultures have had limited success in long-term survival, but cultures of epithelial explants have shown continued long-term regeneration under certain conditions. ${ }^{10}$ Given the previous success at transplantation of olfactory epithelium to the parietal cortex in our laboratory and in the research of other authors, ${ }^{11}$ we sought to further assess the survivability of epithelial transplants in mice and their use as a model for studying the regenerative capacity of this neuroepithelium. In addition, by using antibodies known to have specific staining patterns in control animals, we compared the immunohistochemical staining of transplants with the adult olfactory epithelium.

\section{MATERIALS AND METHODS}

\section{Transplantation Procedure}

Animals used as donors for transplantation of olfactory epithelium were taken from our transgenic mouse breeding colonies maintained in an environmentally controlled disease-free facility. We selected genetically engineered mice with a genetic marker (lacZ) to identify all donor cells within the recipient animal (B6,129-Gtrosa26, The Jackson Laboratory, Bar Harbor, ME) or to localize a specific olfactory neuron receptor subtype (P2-IRES- $\tau$-lacZ, gift of Dr. Richard Axel). ${ }^{12}$ Donor animals were taken at postnatal day 5 to day 20, anesthetized with cold carbon dioxide, decapitated, and dissected in fresh culture medium (Dulbecco's modified Eagle's medium, Life Technologies, Grand Island, NY) over ice. Olfactory epithelium removed from the septum and portions of turbinate tissue were cut in small fragments that were approximately $2 \mathrm{~mm}$ in diameter and stored briefly in fresh culture medium cooled over ice. At the same time, adult wild-type mice (C57BL/6, Harlan, Indianapolis, IN) were anesthetized using sodium pentobarbital injections $(60 \mathrm{mg} / \mathrm{kg}$, intraperitoneally). The surface of the skull was surgically exposed, and a dental drill with a small bur was used to create a small bone flap over the parietal cortex. The surgical site was kept moist with balanced salt solution. Custom-shaped jeweler's forceps were used to insert the fragment of olfactory epithelium approximately 2 to $3 \mathrm{~mm}$ into the parietal cortex (Fig. 1A). A small, blunt-tipped glass rod was applied to the surface of the cortex to prevent extrusion of the epithelium after removal of the forceps. Then the bone flap was replaced, and the skin margins were reapproximated with 3-0 silk suture. Recipient animals were allowed to recover under a heat lamp until the anesthetic was metabolized and were returned to their home cage. The Institutional Animal Care and Use Committee of Virginia Commonwealth University (Richmond, VA) approved all surgical procedures and animal care protocols.

\section{Bromodeoxyuridine Labeling}

To identify epithelial cells synthesizing DNA and therefore undergoing mitosis, normal adult mice (control animals) and transplant recipients were injected intravenously with 
bromodeoxyuridine (BrdU) (Sigma Chemical Company, St. Louis, MO) at a dose of $90 \mathrm{mg}$ / $\mathrm{kg}$. Animals were placed on a heating pad to dilate tail veins, and $\mathrm{BrdU}$ was injected as a single bolus 1 hour before perfusion. This allowed for incorporation of BrdU into the DNA of dividing cells.

\section{Tissue Processing}

Transplant recipients were allowed to survive for time periods of 25, 30, 60, 100,113, and 120 days. Normal adult (control) animals and transplant recipients were deeply anesthetized with sodium pentobarbital injection ( $100 \mathrm{mg} / \mathrm{kg}$ intraperitoneally) and perfused with $4 \%$ paraformaldehyde in phosphate buffer preceded by a phosphate-buffered saline (PBS) rinse through an intracardiac route. The nose of normal adult animals and the brain of recipient animals were removed and postfixed by immersion under vacuum for 1 hour. The nasal skeleton and recipient brains were placed in decalcification solution of saturated ethylenediamine tetraacetic acid at $\mathrm{pH} 7.0$ for 3 days. The tissue was cryoprotected with a $30 \%$ sucrose solution for 2 to 3 days, then immersed in optimal cutting temperature (OCT) embedding compound (Tissue-Tek, Sakura Finetek, Torrance, CA) for 24 hours. Then the tissue was snap-frozen in liquid nitrogen and sectioned on a cryostat in the coronal plane at 8 to $10 \mu \mathrm{m}$ (Fig. 1B). In one case, two $25-\mu \mathrm{m}$ sections were obtained from the center of a transplant for analysis with the scanning electron microscope.

\section{Immunohistochemistry}

Immunohistochemical processing was performed as described previously by Schwob et al. ${ }^{13}$, ${ }^{14}$ Primary antibodies that were used included a polyclonal rabbit antibody directed against olfactory marker protein (OMP) to detect mature olfactory neurons (gift of Dr. Frank Margolis). A monoclonal antibody directed against BrdU was used to detect dividing cells in animals previously injected with the thymidine analogue (B44, Becton Dickinson, San Jose, CA). Mature and immature neurons were labeled with a rabbit polyclonal antibody directed against neural cell adhesion molecule (NCAM) (gift of Dr. James Schwob), and a monoclonal antibody directed against growth-associated protein-43 (GAP-43, Sigma) was used to detect immature neurons. Antibodies were visualized using species specific biotinylated secondary antibodies (Jackson ImmunoResearch Laboratories, Inc., West Grove, PA) and either an avidinbiotinylated horseradish peroxidase system (Vectastain Elite ABC Kit, Vector Laboratories, Burlingame, $\mathrm{CA}$ ) with diaminobenzidine (DAB) as a chromogen or a fluorescently labeled streptavidin complex (Jackson ImmunoResearch Laboratories, Inc.). The monoclonal antibodies were also visualized using a mouse-on-mouse kit (MOM Kit, Vector Laboratories) with either the avidin-biotin peroxidase method or fluorescently labeled streptavidin complex. Except when using the MOM Kit, tissue sections were "blocked" for nonspecific antibody binding by immersing in a solution of $4 \%$ bovine serum albumin (BSA) and 5\% nonfat dry milk dissolved in PBS with $10 \%$ serum. Sections were washed between steps using $0.5 \%$ BSA in PBS or PBS alone. Sections to be stained for BrdU were pretreated with $6 \mathrm{~N}$ hydrochloric acid to denature the DNA. Fluorescent-labeled slides were cover-slipped with Vectashield (Vector Laboratories) mounting medium, and DAB-labeled slides were dehydrated and coverslipped using Cytoseal 60 (Stephens Scientific, Kalamazoo, MI) mounting medium. Labeled sections were viewed using a Nikon Eclipse E600 microscope (Tokyo, Japan) fitted with a fluorescent lamp. Fluorescent labels were visualized using a dual fluorescein isothiocyanateTexas-red filter, and images were captured using a high-resolution digital camera (Coolpix 990, Nikon).

\section{X-Gal Staining}

Selected sections were reacted with $\mathrm{x}$-gal solution to stain cells containing the lacZ gene that is unique to the donor tissue. This allowed confirmation that cells observed in the transplant 
were from the donor and not from the recipient animal. The $\mathrm{x}$-gal staining procedure has been previously described. ${ }^{12}$ In some cases, a combination of $x$-gal reaction and

immunohistochemistry was performed for double labeling. The x-gal reaction was performed first, followed by the immunohistochemistry technique.

\section{Scanning Electron Microscopy}

During routine sectioning on the cryostat, two $25-\mu \mathrm{m}$ sections were obtained from one of the transplants and processed for routine scanning electron microscopy.

\section{RESULTS}

\section{Immunohistochemical Characteristics of Olfactory Epithelium in Adult Mouse}

Immunohistochemical reaction with antibodies directed against OMP labeled an area of cells below the supporting cell layer and above the basal stem cell layer within the olfactory epithelium (Fig. 2A). Olfactory axon bundles within the lamina propria were also labeled with OMP antibodies. Immature neurons with cell bodies located just above the basal cell layer were labeled with antibodies directed against GAP-43 (Fig. 2B). Fibers within the olfactory nerve bundles were also labeled with GAP-43 antibodies. The use of antibodies directed against the NCAM resulted in the labeling of all neurons, both mature and immature, as well as olfactory nerve bundles (Fig. 2C). The combined use of these markers allowed for the identification of olfactory neurons and the differentiation between mature and immature neurons. In addition, labeling with antibodies directed against BrdU in animals previously injected with BrdU identified newly dividing basal stem cells as well as dividing supporting cells (Fig. 2D). These same markers were also used to characterize the epithelial grafts (Figs. 3-6).

\section{General Characteristics of Olfactory Epithelium Grafts to Brain}

Areas of transplanted grafts were identified by the interruption in the normal cerebral cortex architecture. Transplanted grafts were found to be composed of fluid filled vesicles within a cellular matrix. The grafts were well vascularized, and the vesicles were lined with a ciliated epithelium (Fig. 5E and F). The origin of the epithelial cells observed within the transplant region was confirmed to be the donor animal tissue. This was demonstrated by performing the $\mathrm{x}$-gal reaction on transplant tissue harvested from the genetically engineered mice (Figs. 5A and 6B). Total transplant survival combining all survival time points approached $85 \%$.

\section{Mature Olfactory Neurons Found Within Grafts Transplanted to Brain}

Often, epithelium surrounding vesicles within the transplant contained cells labeled with OMP (Fig. 3A). Overall, 34\% of the transplants expressed areas of OMP reactivity. Often, nerve bundles were found in the vicinity of the olfactory epithelium. The transplant epithelium would often take on the layered appearance similar to that found in the normal adult (control) olfactory epithelium. The labeling of transplants with antibodies directed against NCAM identified all neurons including mature neurons labeled with antibodies directed against OMP (Fig. 3B). This finding demonstrated the presence of a population of immature and mature olfactory neurons within the transplant epithelium. The OMP-positive neurons appeared to be oriented with short processes resembling dendrites extending toward the lumen of the vesicle. At the longer survival times (Fig. 4A) OMP-positive labeling was observed, and active cell division was confirmed with BrdU labeling (Fig. 4B).

\section{Transplants Containing Only Immature Neurons Are Rarely Observed}

Transplanting olfactory epithelium to the brain eliminates the olfactory bulbs as a potential target organ. Mature olfactory neurons underwent degeneration, and immature olfactory neurons, presumably, were produced from stem cells within the epithelium. Therefore, it is 
plausible that areas of transplanted epithelium without OMP labeling may be composed of immature neurons that are unable to advance to a stage capable of expressing OMP. However, when labeling transplants with antibodies that recognize immature neurons (GAP-43 or NCAM), it was rare for these markers to be present in the absence of OMP labeling. In most cases, transplants devoid of OMP labeling were without GAP-43 or NCAM labeling even though there was evidence of continued cell division within the epithelium (Fig. 5B-D). When GAP-43 labeling did occur within the epithelium, OMP-positive staining in the vicinity was almost always observed (Fig. 6). The OMP-negative/NCAM-negative epithelium was much thinner with occasional goblet-like cells similar to that found in respiratory epithelium (Fig. $5 \mathrm{~A}$ and $\mathrm{B})$.

\section{DISCUSSION}

Olfactory epithelium obtained from mice on postnatal day 5 to day 20 was successfully transplanted to the brain of adult mice. Viable epithelium was identified at survival times of up to 120 days. Survival of epithelium within the transplants approached $85 \%$. Often, the transplant epithelium reorganized into vesicle-like structures with a lining of epithelium resembling the olfactory epithelium of adult (control) animals (Figs. 3A and 4A); however, the transplant epithelium was typically thinner. These findings are similar to those reported for epithelium transplanted to the anterior chamber of the eye. ${ }^{6}$ Mature neurons identified using antibodies directed against the olfactory marker protein could be found in up to $34 \%$ of all epithelium transplanted to the brain. In transplants with epithelium resembling normal adult olfactory epithelium, axons converged into bundled fascicles. The finding of BrdU-positive dividing cells in areas of OMP-positive cells suggests the presence of regenerating olfactory neurons within the transplant.

All transplants with epithelium were found to contain dividing cells; however, a majority of transplants contained epithelium without mature olfactory neurons. This epithelium possibly could be composed of immature olfactory neurons that are not labeled with anti-OMP antibodies; however, we found that GAP-43 and NCAM antibody staining is typically lacking as well in these cases. The epithelium is thinner and sometimes contains cells resembling respiratory-like goblet cells. The cell surface also contains an abundance of cilia typical of respiratory epithelium. This regression of the olfactory epithelium to a respiratory type has been observed in other animal models. Olfactory epithelium in the normal adult human tends to regress and become replaced by respiratory epithelium, ${ }^{15-17}$ and in aged mice there is thinning of epithelium with a decreased number of olfactory dendrite knobs. ${ }^{18}$ Often, olfactory epithelium lesioned with chemicals is only partially replaced with neuroepithelium and the remainder is replaced with respiratory-type epithelium. ${ }^{19}$ Human olfactory epithelium biopsy specimens from viral-induced anosmic patients have shown absence of olfactory receptor cells with an increase in supporting and basal cells. ${ }^{20}$ This regression to respiratory-type epithelium has also been observed in explant cultures of olfactory epithelium within our laboratory.

The finding of mature olfactory neurons in transplants after 100 days' survival supports the ability of grafted olfactory epithelium to regenerate olfactory neurons. It is not known whether these cells can function as normal receptor cells; however, their orientation within the epithelium is similar to that observed in control specimens, and axon convergence into bundles is also observed within the transplant epithelium. The inconsistent finding of olfactory neurons in transplants may be a function of the grafting technique given that each different survival time observed had a similar percentage of transplants containing mature olfactory neurons. Improved dissection technique and handling of graft tissue may increase numbers of transplants containing olfactory neurons. In addition, the length of time between harvesting the donor epithelium and the surgical transplantation into the recipient brain increases when there are multiple recipients of tissue from a single donor animal. Dissection is performed in cooled, 
balanced culture medium to avoid excessive cell death; however, the olfactory neurons and stem cells may be especially sensitive to these environmental changes, and failure to recognize this may lead to decreased yield of mature olfactory neurons in the surviving transplants. It is also possible that epithelium obtained from animals on postnatal day 5 to day 10 may contain stem cells that are not yet committed to the generation of olfactory epithelium and therefore are easily forced into a respiratory pathway. This is less likely, because of the mature pattern of olfactory epithelium found in rats at these ages, ${ }^{21}$ but could easily be tested by using adult donors.

The addition of neuronal growth factors could be included in future experiments to enhance the numbers of mature olfactory neurons. Growth factors may not be available to the transplant epithelium once it has been removed from the nasal cavity. The distance from the parietal cortex to the olfactory bulbs is probably great enough to eliminate the trophic effects of the target organ, so the addition of various growth factors may improve survival of olfactory nerves as well as axonal growth in transplants. Enhancing the number of regenerating stem cells may also increase numbers of olfactory neurons. This could be achieved by performing olfactory nerve transections in animals before harvesting epithelium and then obtaining donor tissue at time periods known to have maximal regenerating stem cells. The epithelium would then be "primed" for production of receptor neurons, and the transplants may result in a higher percentage of olfactory neurons.

The parietal cortex is a foreign environment for the olfactory epithelium. Epithelial transplants within the brain lack the open exchange of gases available to the epithelium lining the nasal cavity. In the brain parenchyma the olfactory neurons and their growing axons do not have access to their normal target organ, the olfactory bulb. Although it would seem that the olfactory bulb may provide a better environment to support epithelial grafts, preliminary studies have not shown a noticeable improvement in the percentage of olfactory neurons present. Perhaps the best environment for the growth and regeneration of olfactory neurons is within the nasal cavity.

Although grafting directly into the nasal cavity would have direct clinical application for patients with anosmia, we selected the parietal cortex as the transplant site for our initial studies of regeneration and axon growth. In the mouse, the parietal cortex is accessible and has a rich vascular supply, and fibrosis and scar formation are limited. Grafting into the nasal cavity was not selected because of restricted surgical access, inflammatory response, fibrosis, and potential obstruction of the nasal airway. Having first determined basic transplant parameters in the parietal cortex, we have established a reference model to evaluate future methods of grafting in other sites. For example, mucosal defects and cerebrospinal fluid leaks in the nasal cavity encountered with nasal sinus disease, trauma, or surgery are often repaired with grafts containing respiratory epithelium. Perhaps in the future, repair with olfactory epithelium grafts may allow for restoration of olfactory function and provide a new approach to the treatment of patients with anosmia.

\section{CONCLUSION}

Olfactory dysfunction is a disorder overlooked by many physicians, with profound implications for the individual experiencing the loss. New research models for studying olfactory regeneration are needed to enable manipulation of the microenvironment and to optimize neuronal replacement and restoration of function. Transplantation of olfactory epithelium to the parietal cortex may provide a stable environment for studying the regenerative capacity of the olfactory basal or stem cells. Axonal convergence and target guidance may also be studied using this model, and the pluripotent nature of olfactory stem cells with their ability to form neurons makes them a logical choice for future studies in repairing brain lesions. The ability 
to successfully transplant olfactory epithelium to the brain provides us with a valuable tool for studying the process of regeneration and olfactory disease. This knowledge will also assist us in future research directed toward grafting olfactory epithelium within the nasal cavity. If successful, olfactory epithelium grafts in the nasal cavity will provide a new research model with the possibility of reversing certain causes of olfactory dysfunction.

\section{Acknowledgments}

Supported by the Thomas F. Jeffress and Kate Miller Jeffress Memorial Trust and NIDCD grant DC00165.

\section{BIBLIOGRAPHY}

1. Jones N, Rog D. Olfaction: a review. J Laryngol Otol 1998;112:11-24. [PubMed: 9538440]

2. Kimmelman CP. Clinical review of olfaction. Am J Otolaryngol 1993;14:227-239. [PubMed: 8214314]

3. Graziadei PPC, Monti Graziadei GA. Neurogenesis and neuron regeneration in the olfactory system of mammals, I: morphological aspects of differentiation and structural organization of the olfactory sensory neurons. J Neurocytol 1979;8:1-18. [PubMed: 438867]

4. Goldstein BJ, Fang H, Youngentob SL, Schwob JE. Transplantation of multipotent progenitors from the adult olfactory epithelium. Neuroreport 1998;9:1611-1617. [PubMed: 9631475]

5. Huard JM, Youngentob SL, Goldstein BJ, Luskin MB, Schwob JE. Adult olfactory epithelium contains multipotent progenitors that give rise to neurons and nonneuronal cells. J Comp Neurol 1998;400:469486. [PubMed: 9786409]

6. Barber PC, Jensen S, Zimmer J. Differentiation of neurons containing olfactory marker protein in adult rat olfactory epithelium transplanted to the anterior chamber of the eye. Neuroscience 1982;7:26872695. [PubMed: 7155346]

7. Novoselov VI, Bragin AG, Novikov JV, Nesterov VI, Fesenko EE. Transplants of olfactory mucosa in the anterior chamber of the eye: morphology, electrophysiology, and biochemistry. Dev Neurosci 1983-84;6:317-324. [PubMed: 6681367]

8. Amemori T, Soukup T, Bures. Olfactory neuroepithelium transplanted onto the parietal cortex of rats: electroolfactogram in absence of connections with the host brain. Int J Neurosci 1987;34:35-48. [PubMed: 3610502]

9. Magrassi L, Graziadei PPC. Lineage specification of olfactory neural precursor cells depends on continuous cell interactions. Dev Brain Res 1996;96:11-27. [PubMed: 8922664]

10. Farbman AI. Differentiation of olfactory receptor cells in organ culture. Anat Rec 1977;189:187200. [PubMed: 911043]

11. Morrison EE, Graziadei PPC. Transplants of olfactory mucosa in the rat brain, I: a light microscopic study of transplant organization. Brain Res 1983;279:241-245. [PubMed: 6640344]

12. Mombaerts P, Wang F, Dulac C, et al. Visualizing an olfactory sensory map. Cell 1996;87:675-686. [PubMed: 8929536]

13. Schwob JE, Mieleszko Szumowski KE, Stasky AA. Olfactory sensory neurons are trophically dependent on the olfactory bulb for their prolonged survival. J Neurosci 1992;12:3896-3919. [PubMed: 1403089]

14. Schwob JE, Youngentob SL, Meiri KF. On the formation of neuromata in the peripheral olfactory system. J Comp Neurol 1994;340:361-380. [PubMed: 8188856]

15. Naessen R. The identification and topographical localisation of the olfactory epithelium in man and other mammals. Acta Otolaryngol (Stockh) 1970;70:51-57. [PubMed: 4917513]

16. Nakashima T, Kimmelman CP, Snow JB. Structure of human fetal and adult olfactory epithelium. Arch Otolaryngol 1984;110:641-646. [PubMed: 6477257]

17. Paik SI, Lehman MN, Seiden AM, Duncan HJ, Smith DV. Human olfactory biopsy: the influence of age and receptor distribution. Arch Otolaryngol Head Neck Surg 1992;118:731-738. [PubMed: 1627295]

18. Breckenridge LJ, Cameron J, Puri N, Reid O, McGadey J, Smith RA. Localised degeneration occurs in aged mouse olfactory epithelium. J Anat 1997;191:151-154. [PubMed: 9279666] 
19. Schwob JE, Youngentob SL, Mezza RC. The reconstitution of the rat olfactory epithelium after methyl bromide-induced lesion. J Comp Neurol 1995;359:15-37. [PubMed: 8557844]

20. Yamagishi M, Hasegawa S, Nakano Y. Examination and classification of human olfactory mucosa in patients with clinical olfactory disturbances. Arch Otol Rhinol Laryngol 1988;245:316-320.

21. Holbrook EH, Mieleszko Szumowski KE, Schwob JE. An immunochemical, ultrastructural, and developmental characterization of the horizontal basal cells of rat olfactory epithelium. J Comp Neurol 1995;363:129-146. [PubMed: 8682932] 

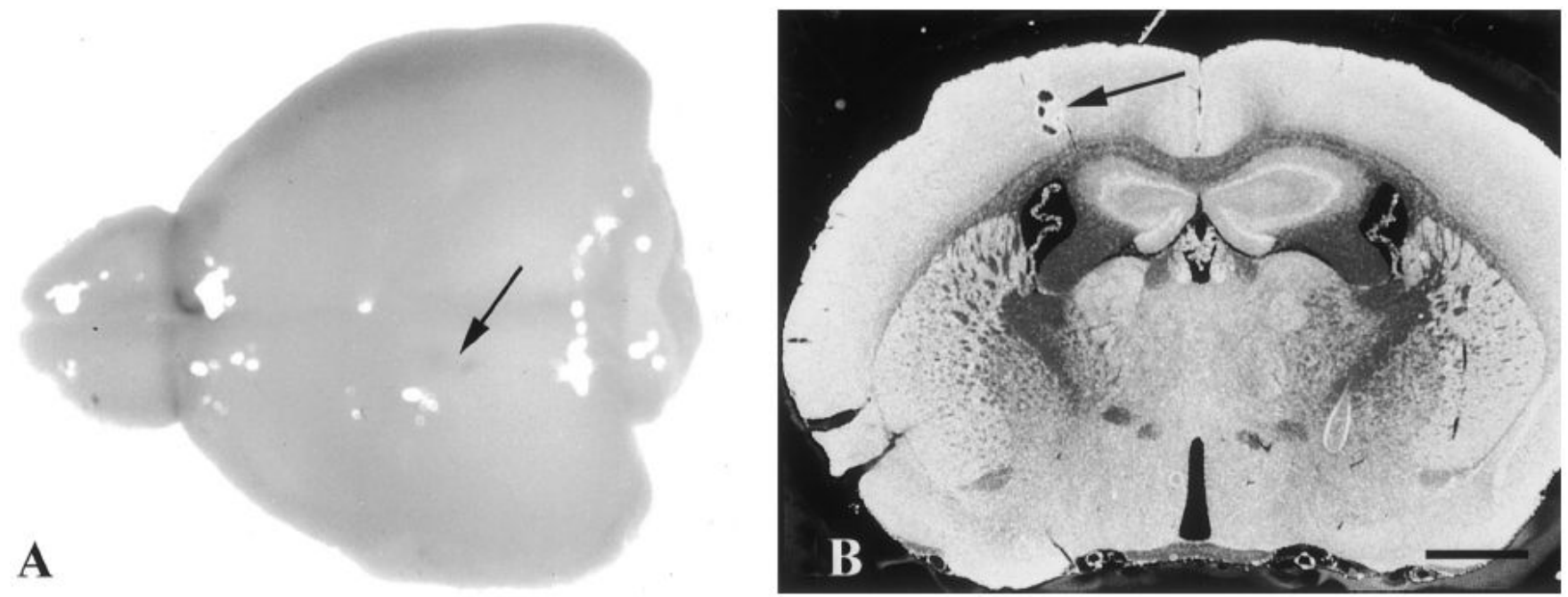

Fig. 1.

(A) Adult mouse brain showing location of transplantation site in the parietal lobe (arrow). (B) Dark-field micrograph of a coronal section through the transplant (arrow) in the parietal cortex. Scale bar $=1000 \mu \mathrm{m}$. 

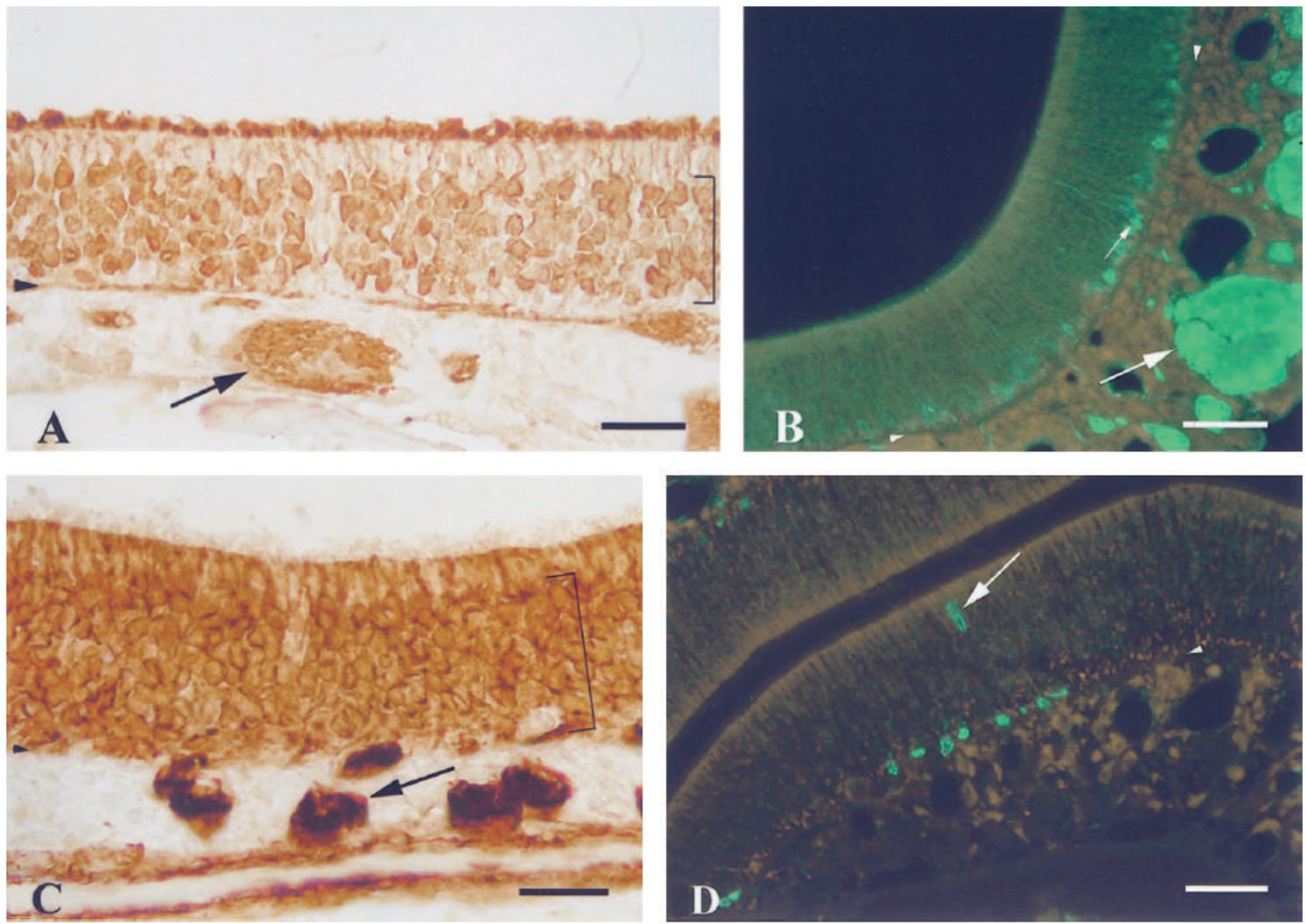

Fig. 2.

Immunostaining of adult control olfactory epithelium. (A) Labeling with olfactory marker protein (OMP) antibodies identifies a zone of mature olfactory neurons (bracket) and axon bundles within the lamina propria (arrow). (B) Labeling with anti-growth-associated protein-43 (anti-GAP-43) antibodies identifies a population of immature olfactory neurons with cell bodies located just above the basal cell layer (small arrow) and axon bundles within the lamina propria (arrow). The dendrite extending to the epithelial surface from the labeled immature olfactory neuron is evident. (C) All neurons within the epithelium, as well as olfactory axon bundles within the lamina propria (arrow), are labeled with antibodies directed against neural cell adhesion molecule (NCAM) (bracket). (D) Multiple dividing basal stem cells, as well as an occasional dividing supporting cell (arrow), are labeled with anti-BrdU antibodies (arrowhead). Scale bars $=30(\mathbf{A}), 40(\mathbf{C})$, and $50(\mathbf{B}$ and D) $\mu \mathrm{m}$. 

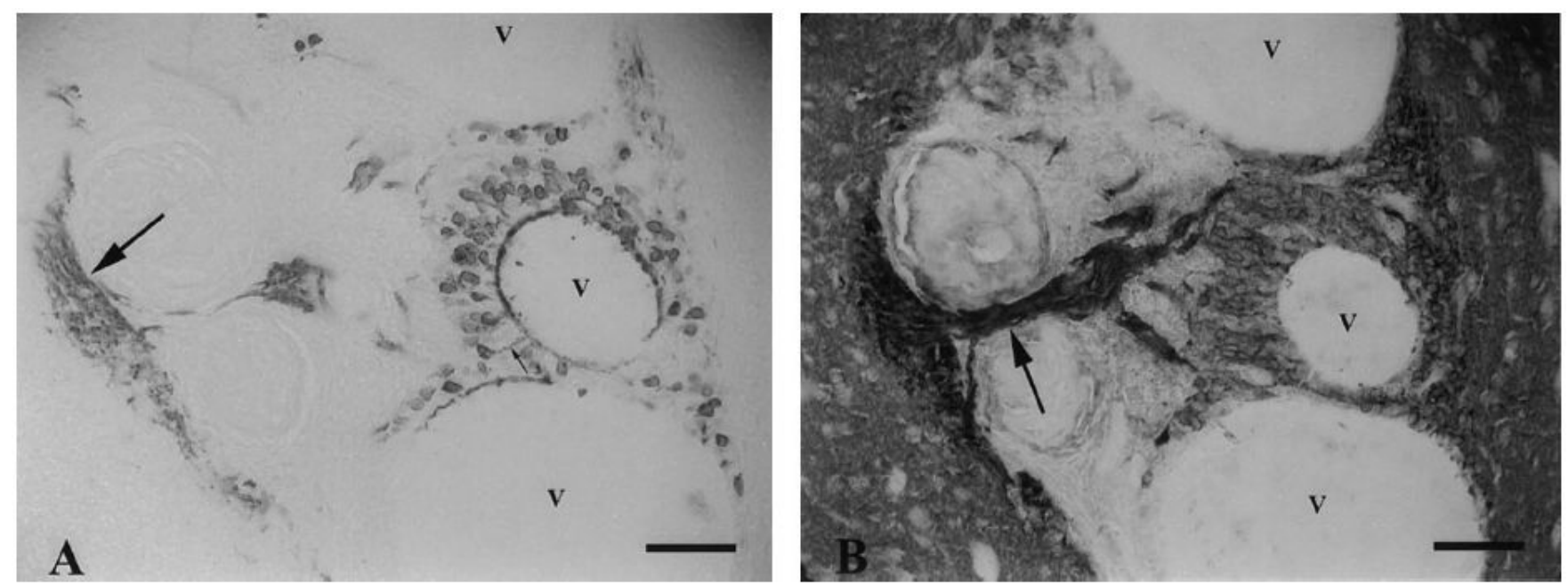

Fig. 3.

Olfactory epithelium transplant after 60 days contains vesicles lined with an epithelium containing mature and immature neurons. (A) Anti-OMP antibodies label the population of mature olfactory neurons surrounding a vesicle. Dendrites extending toward the lumen (small arrow) are evident. (B) Antibodies against NCAM label additional cells within the same transplant epithelium indicating the presence numerous immature olfactory neurons. $\mathrm{V}=$ vesicle lumen; arrows indicate axon bundles. Scale bars $=50 \mu \mathrm{m}$. 

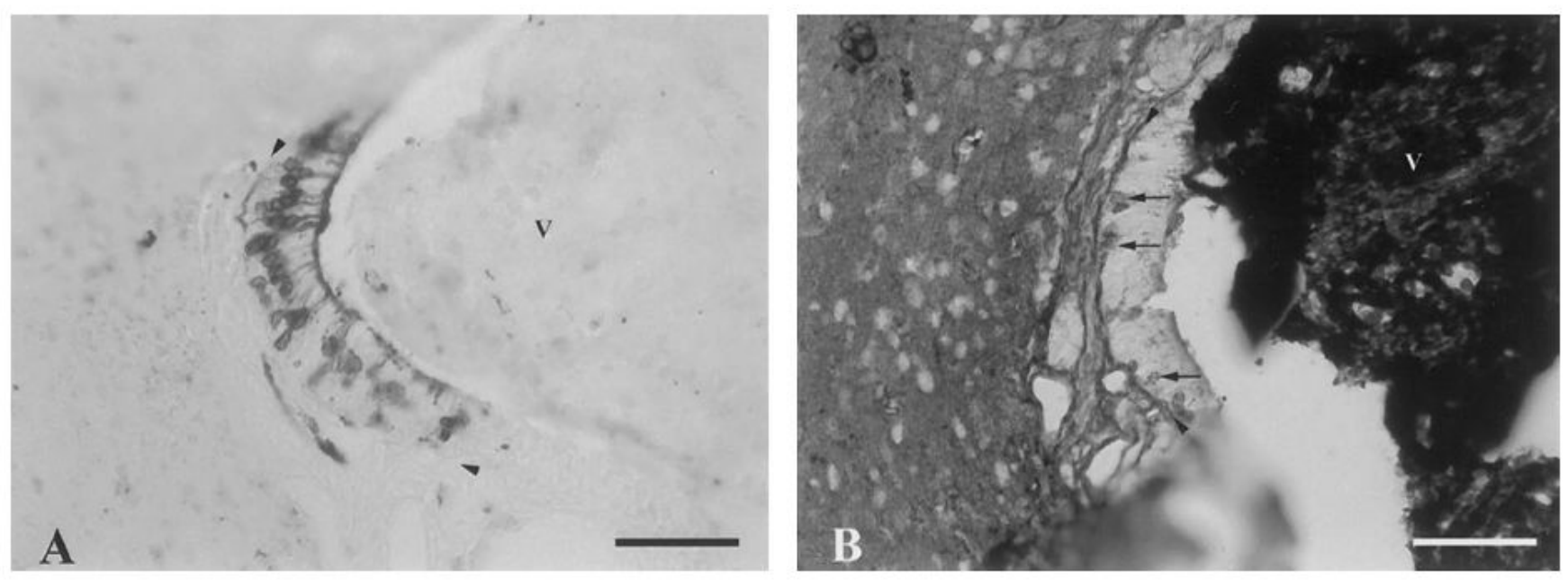

Fig. 4.

Olfactory epithelium transplant after 100 days contains regenerating olfactory neurons. (A) Anti-OMP antibodies label mature olfactory neurons in a pattern similar to adult control epithelium. (B) Anti-BrdU antibodies label dividing basal stem cells (small arrows) above the basal lamina (arrowheads). (A and B) Specimens are from nearly adjacent sections of the same transplant. $\mathrm{V}=$ vesicle lumen. Scale bars $=50 \mu \mathrm{m}$. 

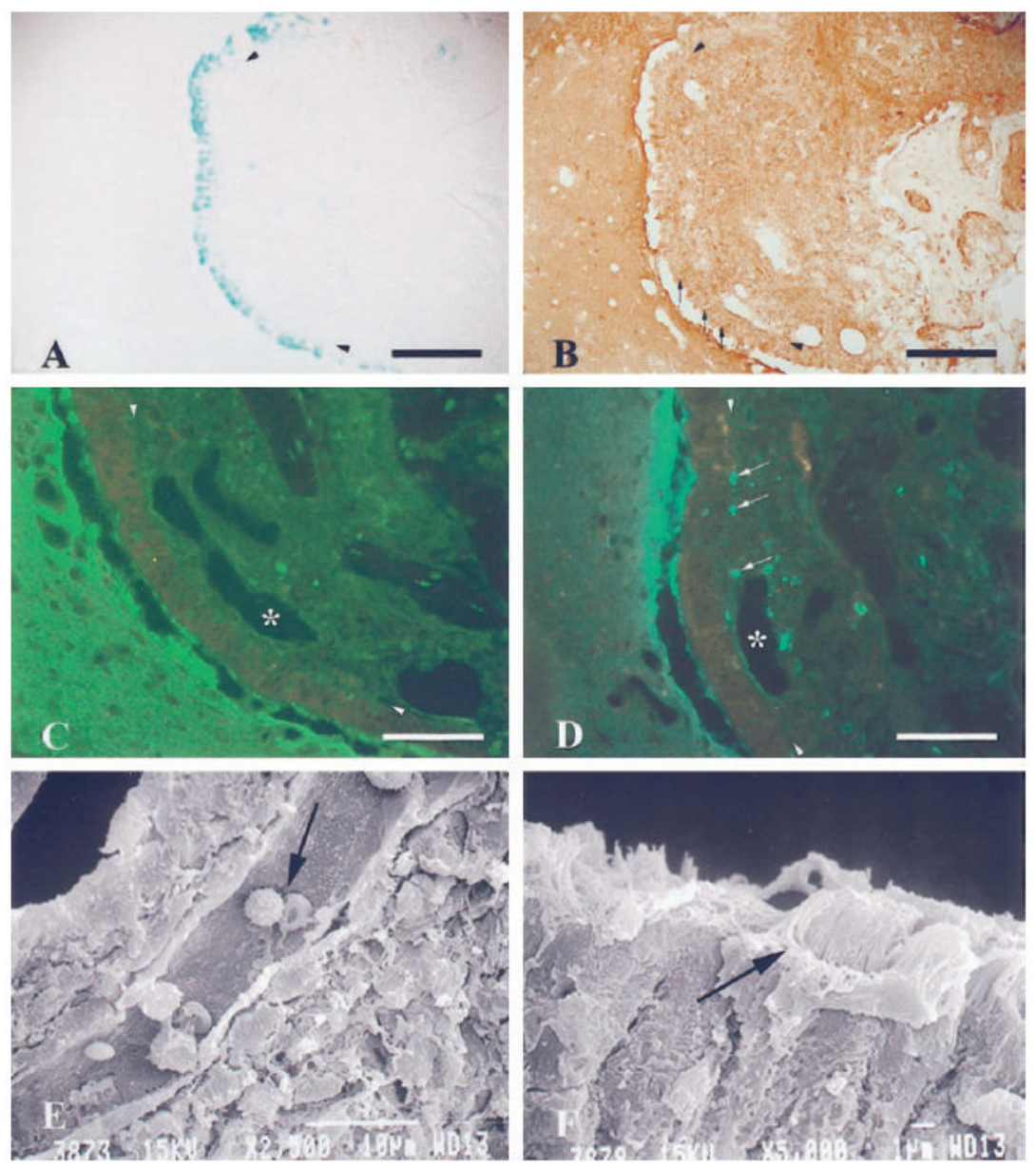

Fig. 5.

An epithelial transplant after 60 days' survival without neuronal components has characteristics similar to respiratory epithelium. (A) The presence of $\mathrm{x}$-gal positive staining in the transplant confirms that the epithelial cells originated from the donor tissue. (B) Anti-OMP staining did not reveal any mature olfactory neurons. Small arrows indicate goblet-like cells in the transplant epithelium. (C) Anti-GAP-43-positive immature neurons were not observed above the basal lamina (arrowheads). (D) Cells labeled with anti-BrdU antibodies indicate that dividing basal stem cells (small arrows) are present in the transplant epithelium. (E) Scanning electron micrograph of a vessel containing blood cells (arrow) indicates vascularization of the transplant. (F) Scanning electron micrograph of the same section at the surface of the epithelium shows abundant cilia similar to those found in respiratory epithelium (arrow). * blood vessel. Scale bars $=(\mathbf{A}$ and $\mathbf{B}) 150,(\mathbf{C}$ and D) $75,(\mathbf{E}) 10$, and $(\mathbf{F}) 1 \mu \mathrm{m}$. 

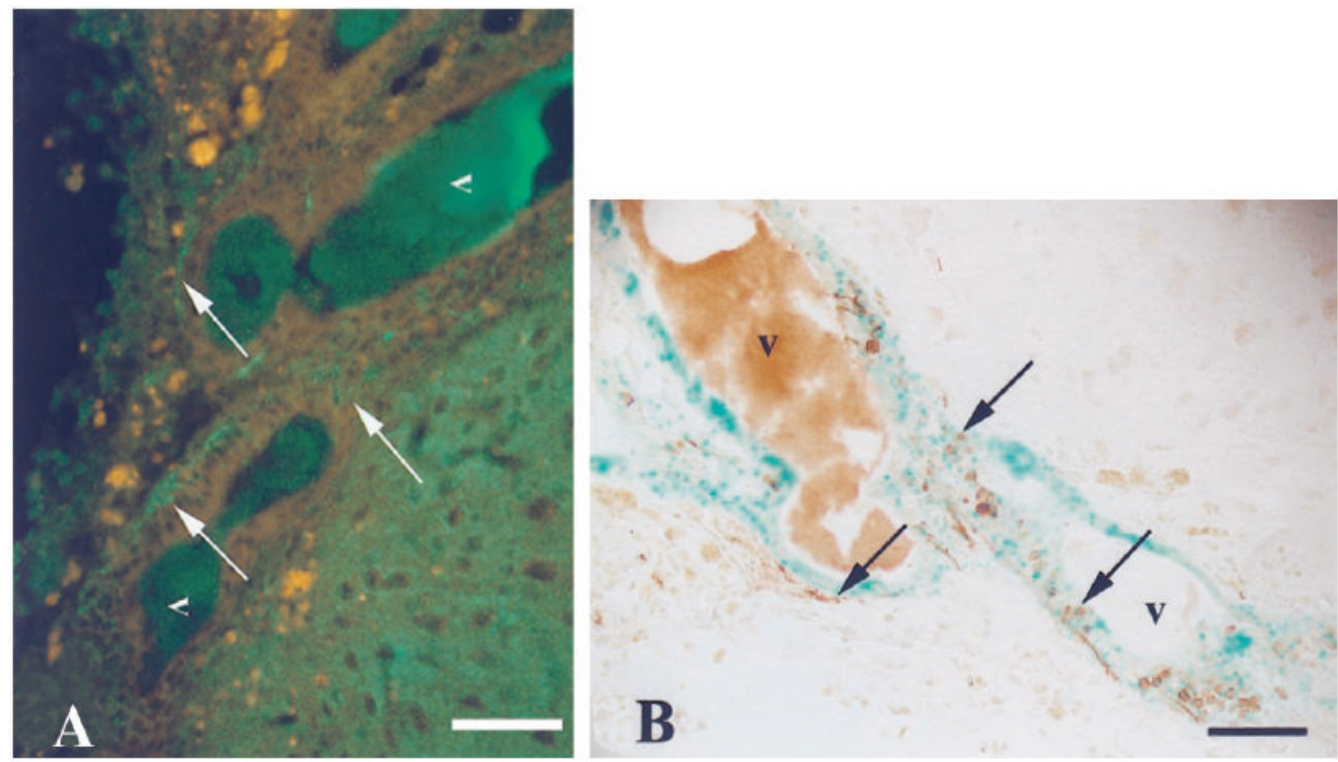

Fig. 6.

Olfactory epithelium transplant after 25 days with mature and immature neurons. (A) Immature neurons labeled with anti-GAP-43 antibodies (arrows). (B) An adjacent section doublelabeled with anti-OMP antibodies (brown) and X-gal (blue) indicates that the transplant contains mature olfactory neurons which originated from the donor tissue. Arrows show areas labeled with antiOMP and anti-GAP-43 antibodies. V = vesicle lumen. Scale bars $=50 \mu \mathrm{m}$. 